\title{
ALGUMAS REFLEXÕES SOBRE INTERFACES \\ DA PANDEMIA DA COVID-19: QUANDO \\ UM VÍRUS CONVOCA A HUMANIDADE A \\ "OUTRAR-SE"
}

\author{
Fabiane Ferraz \\ Cristiane Damiani Tomasi \\ Luciane Bisognin Ceretta \\ Jacks Soratto
}

DOI: http://dx.doi.org/10.18616/intcovO1

Em dezembro de 2019, em um mercado de frutos do mar na cidade de Wuhan, capital da província Hubei, na China, houve notificação do primeiro caso de uma pneumonia inespecífica que posteriormente seria caracterizada como o um novo tipo de coronavírus, denominado Sars-CoV-2 causador da covid-19.

Esse agravo específico atingiu exponencialmente um número considerável de pessoas sendo atribuído como uma pandemia no dia 11 de março de 2020 pela Organização Mundial da Saúde (OMS).

Essa pandemia produziu medo, insegurança, desespero, angustia, dor, sofrimento, desesperança, saudades... Mas também, foi um ano de oportunidades, de ressignificação, de resiliência, de compreensão, de cooperação, de amparo, de solidariedade, de compaixão, de convite a enxergarmos "querendo ver" o/a outro/a, enfim, de desenvolvermos a tão importante alteridade.

$\mathrm{O}$ que moveu, e ainda move as pessoas a se conectarem a um, ou a outro sentimento/sensações? Será que é a capacidade de empatia, de se importar? Sim, se importar com o/a outro/a, com o "outro" mais próximo - nossos familiares e amigos/as; ou o "outro" distante - quem nem conhecemos, mas acompanhamos pela mídia ou redes sociais "virar estatística", ou aquele "outro" que exerce a função profissional de cuidar de quem adoece, ou aqueles "outros" aos quais as medidas restritivas e de cuidados para evitar a covid-19 não produzem sentidos, pelo simples fato, que não têm como manterem-se isolados se, o poder público, não prover um efetivo sistema de proteção social (FELICIELLO; GAVA, 2020). Àqueles "ou- 
tros" que sim, a pandemia mostra sua face mais cruel, pois a essas pessoas não há opção de escolha, visto que não estão vivendo apenas "um ano difícil", mas, sim, suas vidas são muito difíceis, e infelizmente, em nossa sociedade, são valoradas de formas distintas.

Frente a isso, percebemos que, uma das possibilidades que a situação que vivenciamos nos convoca é a de "outrar-se”. Mas o que é isso? Que convocação é essa? Que implicação ela nos causa? Será que enquanto seres humanos, temos realmente essa capacidade?

Gomes (2005), em seu artigo "Adeus ao eu: a enunciação do outrar-se", analisa essa expressão a partir da perspectiva de grandes pensadores da atualidade como Bakhtin, Deleuze, Benveniste bem como referencia a compreensão do maior poeta da língua portuguesa, Fernando Pessoa quando refere que no "outrar-se" temos o devir do "eu como um outro". Mas em meio a grandes filósofos e pensadores do nosso tempo, como produzir sentido ao termo de uma forma que todos/as consigam compreender? Assim, também buscamos esse termo em espaços que o senso comum procura, e encontramos que "outrar-se” na Infopédia é definido como “[...] deixar-se contagiar por algo de sentido novo e diferente (por exposição a culturas, climas, linguagens, pensamentos), deixando-se transformar num ser novo, distinto, que veste uma nova personalidade ou forma de estar no mundo".

Nesse sentido, o convite realizado pelo Programa de Pós-Graduação em Saúde Coletiva (PPGSCol) da Universidade do Extremo Sul Catarinense (UNESC), era para que os/as autores/as expressassem as suas perspectivas sobre uma pandemia, a intensão foi de permitir. Permitir múltiplas vozes, permitir múltiplas expressões de seu modo de ver e sentir, permitir as mais variadas formas de demonstrar as "faces" de uma pandemia, a fim de que ao lermos os diversos capítulos dessa publicação compreendêssemos que nesses momentos difíceis, vivenciamos a possibilidade de nos resignificarmos, de "outrar-se".

A construção do conhecimento é um desafio em todos os tempos, e na situação que estamos vivendo, tornou-se ainda maior. É necessário e ético compreendermos que há muitas "faces" que se interconectam nesse momento. A característica multifatorial da pandemia nos convida a apresentar múltiplos olhares, traduzidos em fatos, cenas e impressões sociais, os quais se destacam em textos críticos, científicos, relatos de experiência, crônicas, poesias e imagens (fotos) que sinalizam aos leitores "a vida” nesse cenário pandêmico. 
Assim, esse material possibilitou dar visibilidade e dizibilidade a 67 obras que expressam concepções, experiências e imagens que denotam com criticidade e sensibilidade as situações do cotidiano, deixando mais nítido as movimentações que aconteceram no campo teórico, acadêmico, social e político vivenciado no estado de Santa Catarina, Brasil.

As produções científico-literárias e fotográficas traduzem as dificuldades encontradas para manutenção da vida e superação das difíceis condições que boa parte da população vivenciou. Mas também, reportam a capacidade de reinvenção daquilo que outrora nunca foi modificado. Desejamos que as reflexões produzidas por essa obra, estruturada por múltiplas mãos, efetivamente nos mobilize a "outrar-se".

\section{REFERÊNCIAS}

FELICIELLO, Domenico; GAVA, Gustavo Bonin. Economia e pandemia: lockdown, flexibilização e defesa da vida. Cadernos de Pesquisa NEEP, Campinas, v. 89, p. 1-20, set. 2020. Disponível em: https://www.nepp.unicamp.br/upload/documents/publicacoes/bab8beb42dac07efe3ab6e7b6ebfcde9.pdf. Acesso em: 29 nov. 2020. GOMES, José Ney Costa. Adeus ao eu: a enunciação do outrar-se. Kalíope, São Paulo, ano 1, n. 1, p. 93-109, 2005. Disponível em: https://revistas.pucsp.br/ index.php/kaliope/article/view/3143/2075. Acesso em: 30 nov.

OUTRAR-SE. In: INFOPÉDIA. Dicionários. Porto: Porto Editora, 2003-2020. Disponível em: https://www.infopedia.pt/\$outrar-se. Acesso em: 14 dez. 2020.

\section{OBRAS CONSULTADAS}

OLIVEIRA, Adauto Emmerich et al. A Pandemia da covid-19 diante da dor de todos nós: notas para intrusão de uma comunicação social e suas interfaces com a saúde mais cidadã. OZIRIS - Observatório de Risco, Coimbra, Portugal, p. 1-5, 2020. Disponível em:

http://www.ces.uc.pt/ficheiros2/sites/osiris/files/OSIRIS_Adauto $\% 20$ Emmerich\%20Oliveira\%20et\%20al_R.pdf. Acesso em: 29 nov. 2020. 